\title{
Cascade aerobic selective oxidation over contiguous dual catalyst beds in continuous flow
}

\author{
Durndell, Lee
}

http://hdl.handle.net/10026.1/13752

\subsection{1/acscatal.9b00092}

ACS Catalysis

American Chemical Society (ACS)

All content in PEARL is protected by copyright law. Author manuscripts are made available in accordance with publisher policies. Please cite only the published version using the details provided on the item record or document. In the absence of an open licence (e.g. Creative Commons), permissions for further reuse of content should be sought from the publisher or author. 
Subscriber access provided by UNIV OF PLYMOUTH

\section{Article}

\section{Cascade aerobic selective oxidation over contiguous dual catalyst beds in continuous flow}

Lee J Durndell, Mark A. Isaacs, Chao'en LI, Christopher Parlett, Karen Wilson, and Adam Fraser Lee

ACS Catal., Just Accepted Manuscript • DOI: 10.1021/acscatal.9b00092 • Publication Date (Web): 29 Apr 2019

Downloaded from http://pubs.acs.org on April 30, 2019

\section{Just Accepted}

"Just Accepted" manuscripts have been peer-reviewed and accepted for publication. They are posted online prior to technical editing, formatting for publication and author proofing. The American Chemical Society provides "Just Accepted" as a service to the research community to expedite the dissemination of scientific material as soon as possible after acceptance. "Just Accepted" manuscripts appear in full in PDF format accompanied by an HTML abstract. "Just Accepted" manuscripts have been fully peer reviewed, but should not be considered the official version of record. They are citable by the Digital Object Identifier (DOI®). "Just Accepted" is an optional service offered to authors. Therefore, the "Just Accepted" Web site may not include all articles that will be published in the journal. After a manuscript is technically edited and formatted, it will be removed from the "Just Accepted" Web site and published as an ASAP article. Note that technical editing may introduce minor changes to the manuscript text and/or graphics which could affect content, and all legal disclaimers and ethical guidelines that apply to the journal pertain. ACS cannot be held responsible for errors or consequences arising from the use of information contained in these "Just Accepted" manuscripts. 


\title{
Cascade aerobic selective oxidation over contiguous dual catalyst beds in continuous flow
}

\author{
Lee J. Durndell, ${ }^{\text {a }}$ Mark A. Isaacs, ${ }^{\mathrm{b}}$ Chao'en Li, ${ }^{\mathrm{c}}$ Christopher M.A. Parlett, ${ }^{\mathrm{d}, \mathrm{e}}$ Karen Wilson ${ }^{\mathrm{f}}$ and Adam F. Lee ${ }^{\mathrm{f}}$

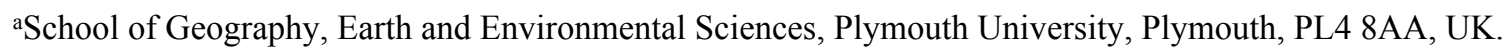 \\ ${ }^{b}$ Department of Chemistry, University College London, London, WC1E 6BT, UK. \\ cCSIRO Energy, 71 Normanby Road, Clayton North, Victoria 3169, Australia. \\ ${ }^{\mathrm{d} S}$ School of Chemical Engineering and Analytical Science, University of Manchester, Manchester M13 9PL, UK. \\ eDiamond Light Source Ltd, Harwell Science and Innovation Campus, Didcot OX11 0DE. \\ fSchool of Science, RMIT University, Melbourne VIC 3001, Australia. \\ "Corresponding author e-mail: adam.lee2@rmit.edu.au
}

\begin{abstract}
Cascade reactions represent an atom-economical and energy efficient technology by which to reduce the number of manipulations required for chemical manufacturing. Biocatalytic cascades are ubiquitous in nature, however controlling the sequence of interactions between reactant, intermediate(s), and active sites, remains a challenge for chemocatalysis. Here we demonstrate an approach to achieve efficient cascades using chemical catalysts through flow chemistry. Close-coupling of Pd/SBA-15 and Pt/SBA-15 heterogeneous catalysts in a dual bed configuration under continuous flow operation, affords a high single pass yield of $84 \%$ (a 20 -fold enhancement over batch operation) and high stability for $>14,000$ turnovers in the cascade oxidation of cinnamyl alcohol to cinnamic acid, despite both catalysts being individually inactive for this reaction. Judicious ordering of Pd (first bed) and Pt (second bed) catalysts is critical to promote cascade oxidation with respect to undesired hydrogenation and hydrogenolysis; the latter favoured over the reverse bed sequence or a single mixed PdPt reactor bed. The intrinsic catalytic performance of each bed is preserved in the optimal dual bed configuration, enabling quantitative prediction of final product yields for reactants/intermediates whose individual oxidation behaviour is established. Continuous processing using contiguous reactor beds enables plug-and-play design of cascades employing 'simple' catalysts.
\end{abstract}

Keywords: Cascade; flow chemistry; oxidation; palladium; platinum; alcohol 


\section{INTRODUCTION}

The targeted modification of specific functionalities within complex molecules through chemoselective catalysis is pivotal to achieving a sustainable chemical economy, and the development of biorefineries employing renewable feedstocks to complement (and potentially supplant) the existing petrochemical industry. ${ }^{1-3}$ To this end, selective, multi-step transformations of bio-derived substrates are particularly attractive routes to maximise atom efficiency in chemical synthesis. ${ }^{4-5}$ Cascade aerobic selective oxidations offer one such route to unsaturated carboxylic acids, high value chemical intermediates finding widespread application in the agrochemical, pharmaceutical and fine chemical sectors from their corresponding alcohols (prevalent in nature).$^{6-9}$ For example, cinnamic acid is a flavourant, ${ }^{10}$ an intermediate in phenylalanine production ${ }^{11}$ and as a source of synthetic indigo. ${ }^{12}$ However, the production of $\alpha, \beta$-unsaturated acids over heterogeneous catalysts has proven challenging, since few individual catalysts are able to efficiently oxidise both the initial alcohol and subsequent reactivelyformed carbonyl functions. ${ }^{13-15}$

Supported Platinum Group Metals (PGMs) are effective for the aerobic oxidation of allylic alcohols to aldehydes, with surface oxides identified as the active sites responsible in palladium and platinum catalysts. ${ }^{16-20}$ In the case of cinnamyl alcohol oxidation ( $\mathrm{CinnOH}$ ), electron deficient palladium is $>90 \%$ selective to cinnamaldehyde (CinnALD), but unable to oxidise the reactively-formed cinnamaldehyde to cinnamic acid (CinnAcid) as shown in Scheme $\mathbf{1},{ }^{17}$ in the absence of main group promoters and highly basic conditions. ${ }^{21-23}$ In contrast, electron deficient platinum is only around $65 \%$ selective to cinnamaldehyde, and rapidly deactivates due to competing decarbonylation (to styrene) and hydrogenation (of cinnamaldehyde to 3-phenylpropanoic acid) pathways; the latter driven by surface hydrogen released by the initial oxidative dehydrogenation step which promote platinum reduction to the unselective metal. ${ }^{16}$ Nevertheless, electron deficient platinum is active and $80 \%$ selective towards the oxidation of cinnamaldehyde to cinnamic acid when the pure aldehyde is employed as a substrate. ${ }^{16,24-25}$

Scheme 1. Cascade oxidation of cinnamyl alcohol to cinnamic acid over Pd and Pt catalysts: selectivity from (black) cinnamyl alcohol, or (red) cinnamaldehyde as the initial reactant. ${ }^{16-17,24,26}$

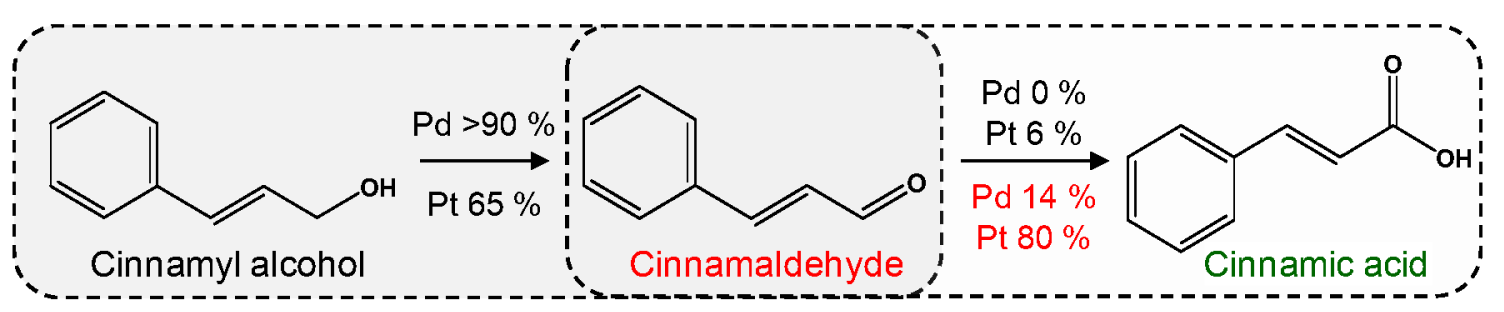


We recently demonstrated the synthesis of a spatially orthogonal, hierarchical Pd macroporous-Pt mesoporous SBA-15 catalyst for this two-step cascade oxidation, however fabrication of such architectures is complex, and optimising the concentration and location of each active site to match the kinetics of each oxidation step is time-consuming. ${ }^{27}$ Continuous flow aerobic oxidations offer significant process benefits over analogous batch reactions, associated with superior mass transport across the three phase (gas-solid-liquid) boundaries and improved safety through minimising the total volume of oxygen-saturated organic solvent; the latter notably when tube-in-tube membrane reactors are employed to separate pure oxidant and organic streams. ${ }^{28-31}$ Flow chemistry has been successfully utilised for the aerobic oxidation of primary alcohols to aldehydes and ketones, and of aldehydes to carboxylic acids. ${ }^{14,32-36}$ However, to our knowledge a sequence of packed catalyst beds has never been employed to facilitate a cascade oxidation, whereby the downstream bed activates a molecular function produced over the upstream bed. This approach obviates the need to develop a single catalyst able to e.g. selectively oxidise both alcohol $\rightarrow$ carbonyl and carbonyl $\rightarrow$ acid, enabling the use of readily available catalysts that are selective for the individual steps. We demonstrate the cascade liquid phase selective oxidation of cinnamyl alcohol to cinnamic acid, through continuous flow operation over contiguous $\mathrm{Pd}$ and $\mathrm{Pt}$ nanoparticle packed beds, highlighting the critical roles of reactor configuration/catalyst sequence on activity and cinnamic acid yield.

\section{RESULTS AND DISCUSSION}

Structural properties of the parent mesoporous SBA- 15 silica support, and wet impregnated $0.5 \mathrm{wt} \% \mathrm{Pd} / \mathrm{SBA}-15$ and $1 \mathrm{wt} \%$ Pt/SBA-15 catalysts are summarized in Table S1 and Figures S1-7. These metal loadings were selected to achieve an (approximately) equal number of $\mathrm{Pd}$ and $\mathrm{Pt}$ atoms to aid direct comparison. The liquid residence time, $\tau$ (defined as the catalyst bed volume/flow rate) was first investigated to determine the system response to the introduction of substrate, and optimum flow rate for cinnamic acid production. Resulting residence time distributions for the normalised response $F(t)$ given by Equation 1, evidenced near plug-flow behaviour for both catalysts and cinnamyl alcohol and cinnamaldehyde substrates (Figure S8); single and dual/mixed catalyst beds are considered static and filled with well-distributed liquid. Reactions were performed in a two-phase (liquid-solid) manner employing an oxygen-saturated solvent stream. The behaviour of different reactor configurations towards continuous oxidation of cinnamyl alcohol, and the cinnamaldehyde intermediate, was subsequently explored (discussed in detail later), and the best performing Pd-Pt sequential dual bed configuration thus identified for optimisation (Figure 1a) as described in the ESI, and benchmarking against batch operation for the cascade oxidation (Figure 1b). The act of placing a Pd catalyst in a separate bed preceding a Pt catalyst delivers a striking performance enhancement compared to a physical mixture of both in the same batch reactor (or either catalyst alone): the dual bed achieved 
$84 \%$ cinnamic yield in flow, and maintained this for $>14,000$ turnovers with negligible deactivation ( $<0.5 \%$ drop); in contrast batch operation delivered only 1-5\% acid yields and $>75 \%$ deactivation after only $5 \mathrm{~h}$ (Figure S9). This achievement is comparable to the best report for any alcohol, but obviates previous requirements for high concentration of additional base (typically $25-100 \mathrm{~mol} \%$ ) and/or exotic catalyst formulations. ${ }^{22}$ Note that staggering the time at which Pd and Pt catalysts were added to the batch reactor (Figure 1a), to more closely mimic the sequential nature of the flow reactor, substantially increased the acid yield to $17 \%$ as discussed later.
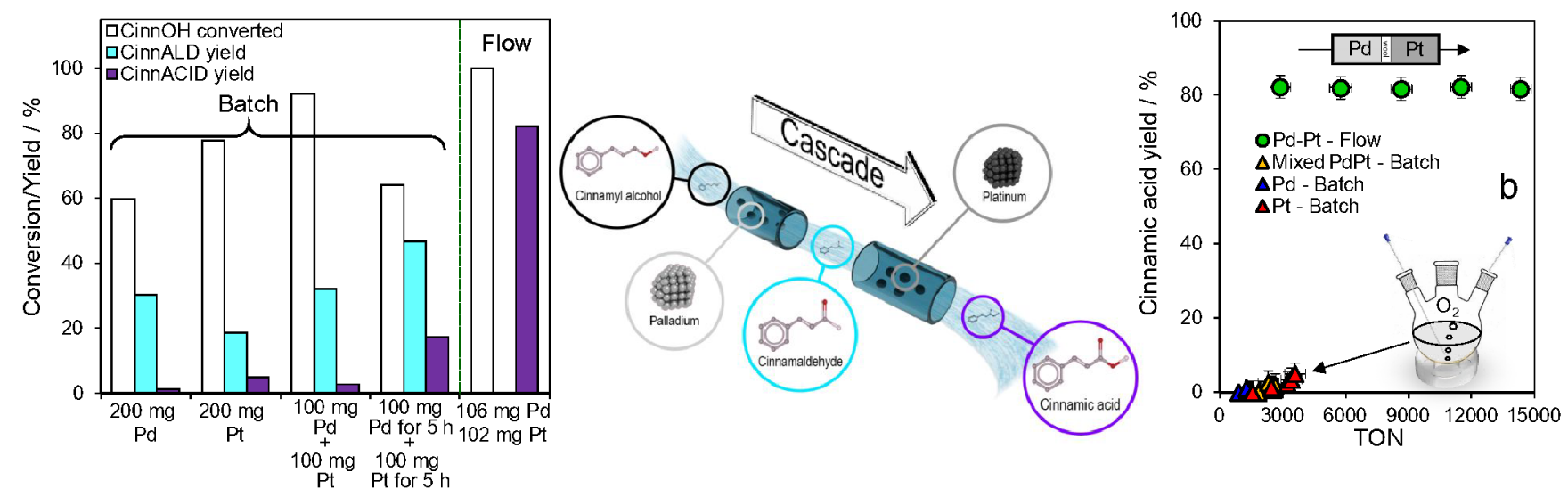

Figure 1. Cascade aerobic oxidation of cinnamyl alcohol to cinnamic acid: (a) in continuous flow over an optimised Pd-Pt sequential dual bed versus monometallic $(\mathrm{Pd}$ or $\mathrm{Pt})$ catalysts or a physical mixture $(\mathrm{Pd}+\mathrm{Pt})$ of catalysts (common total metal content) after $5 \mathrm{~h}$ on-stream versus the staggered addition ( $\mathrm{Pd}$ for $5 \mathrm{~h}$ and then Pt for $5 \mathrm{~h}$ ) of catalysts in batch; (b) cinnamic acid yield in flow versus batch as a function of turnover number (TON). Reaction conditions: $90{ }^{\circ} \mathrm{C}, 5$ bar $\mathrm{O}_{2}, 168 \mathrm{mM}$ cinnamyl alcohol in toluene (flow) or $16.8 \mathrm{mmol}$ cinnamyl alcohol in $50 \mathrm{~cm}^{3}$ toluene (batch), liquid flow $0.2 \mathrm{~cm}^{3} \cdot \mathrm{min}^{-1}(\tau=17$ $\min )$.

The impact of reactor bed configuration was explored to understand the superiority of cascade oxidation in continuous flow across the Pd-Pt sequential dual bed configuration. Smaller catalyst beds were employed to avoid complete conversion and hence enable the observation of performance changes. The influence of residence time on cinnamyl alcohol conversion and product selectivity was studied over monometallic Pt and Pd beds, and physically mixed or sequential dual bed configurations containing both Pd and Pt catalysts (Figure 2 and Figure S10). All reactor configurations exhibited a sigmoidal relationship between alcohol conversion and residence time; minimal $(<10 \%)$ CinnOH conversion was observed for $\tau<5$ min, with longer residence times affording a monotonic increase up to $\tau=\sim 25 \mathrm{~min}$, above which single pass conversions tended to limiting values between $40-80 \%$. We attribute this plateau, and inability to achieve complete alcohol conversion, to either limited 
oxygen availability or catalyst deactivation; the former is discounted since Figure 1a shows an optimised dual bed Pd-Pt configuration can achieve complete conversion, however lifetime experiments confirmed $\sim 50 \%$ deactivation for monometallic systems at this residence time (Figure S11), attributed to catalyst reduction and concomitant poisoning by strongly adsorbed $\mathrm{CO}$ and alkylidyne species. ${ }^{37-38}$ Time dependent product distributions for mono- and bimetallic (dual and mixed bed) reactor configurations were extremely stable (Figure S12). The order of activity at the longest residence time was Pd-Pt $>$ mixed bed $>$ Pt-Pd $>$ Pd $>>$ Pt. It is interesting to note that a physical mixture of the two catalysts performed better both in flow and batch (Figure S13) than either of the monometallic catalysts (at a common total metal content), indicating a modest synergy between the two components when intermixed; this synergy was accentuated by delaying addition of the Pt catalyst in batch operation (Figure 1a). Maximum cinnamyl alcohol conversion for $\tau=>25 \mathrm{~min}$ over the monometallic Pd bed in flow was comparable to that attainable after $5 \mathrm{~h}$ reaction in batch (Figure S13), although the monometallic Pt bed performed significantly better in batch than flow ( $78 \%$ versus $46 \%$ ). These activity differences for different bed configurations were almost eliminated by operation at $\tau=17 \mathrm{~min}$, enabling their selectivity to be compared at a similar $(\sim 30-40 \%)$ conversion. Turnover frequencies (TOFs) for CinnOH conversion normalised to total surface metal oxide (Table S1) for the monometallic Pd and Pt beds were $5,128 \mathrm{~h}^{-1}$ and 8,652 $\mathrm{h}^{-1}$ respectively for $\tau=17 \mathrm{~min}$, comparable to those previously reported in batch ${ }^{16-17}$ of $5,000 \mathrm{~h}^{-1}$ and 6,000 $\mathrm{h}^{-1}$ indicating these flow reactions were free from mass-transport limitations.
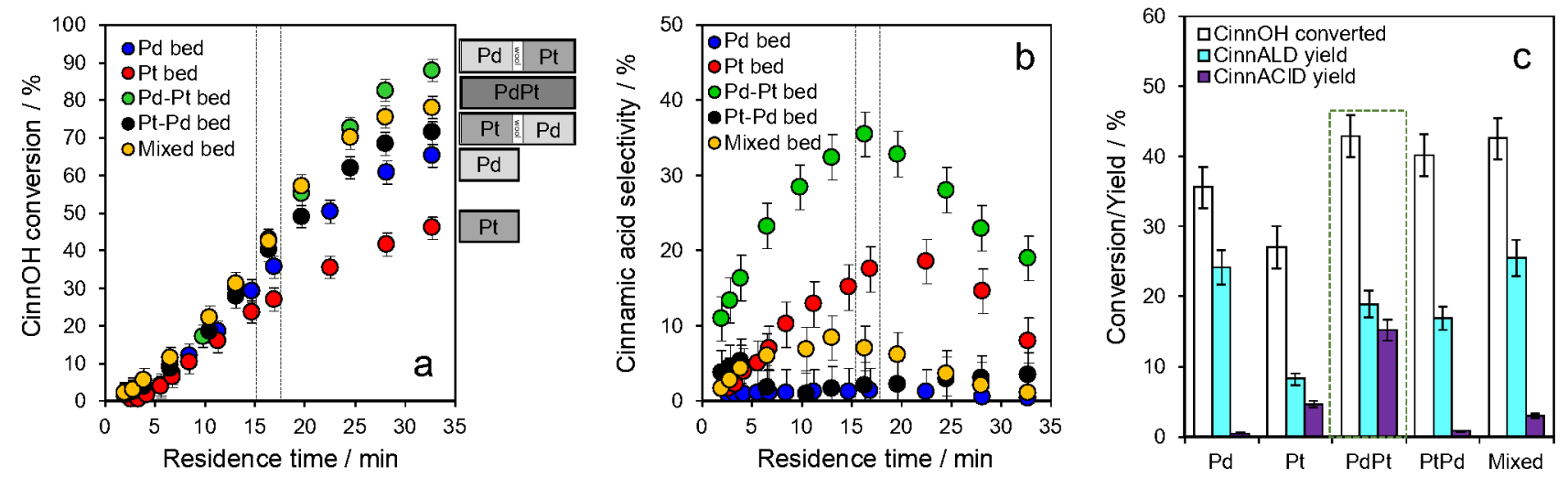

Figure 2. The influence of residence time on (a) cinnamyl alcohol selective oxidation in flow, and (b) corresponding cinnamic acid selectivity over single, sequential dual, and physically mixed catalyst beds, and (c) influence of bed composition on alcohol conversion and product yield for $\tau=17 \mathrm{~min}$. Reaction conditions: $50 \mathrm{mg}$ of catalyst in monometallic beds, $50 \mathrm{mg}$ of each catalyst component in mixed and dual beds (common total metal content); $90^{\circ} \mathrm{C}, 5$ bar $\mathrm{O}_{2}, 168 \mathrm{mM}$ cinnamyl alcohol in toluene, liquid flow rates 0.1 to $2.5 \mathrm{~cm}^{3} \cdot \mathrm{min}^{-1}, 7 \mathrm{~h}$ on-stream. 
Cinnamic acid selectivity demonstrated a striking dependence on reactor configuration (Figure 2b), with the Pd-Pt sequential dual bed and monometallic Pt bed significantly outperforming all other catalyst systems. For both these configurations, cinnamic acid selectivity exhibited a concave relationship with residence time, reaching maxima of $36 \%$ and $18 \%$ respectively around $\tau=17 \mathrm{~min}$; a similar (albeit weaker) relationship was observed for the mixed bed, whereas the monometallic Pd bed and sequential dual bed Pt-Pd produced $<5 \%$ cinnamic acid for all residence times. Figure 2c compares cinnamyl conversion, and the associated yields of the reactively-formed cinnamaldehyde intermediate and cinnamic acid products, at $\tau=17 \mathrm{~min}$. In addition to offering the highest cinnamic acid yield, the Pd-Pt sequential dual bed arrangement also produced significant cinnamaldehyde, which serves as the reservoir for the additional acid production observed in the optimised process in Figure 1. Negligible cinnamic acid conversion was observed over any catalyst in either batch or flow.

Despite its proclivity for the selective oxidation of cinnamyl alcohol to cinnamaldehyde (Figure 3a) for all residence times, poor acid production over the monometallic Pd catalyst can be readily understood from its preferential decarbonylation of cinnamaldehyde to styrene ${ }^{39-40}$ versus oxidation to the acid (Figure 3b-c, Figure S14, and Figure S15a). In contrast, the monometallic Pt catalyst favours aldehyde oxidation to cinnamic acid (Figure 3b, Figure S14, and Figure S15a), with maximum selectivity attained for $\tau=17 \mathrm{~min}$, coincident with that observed for the cascade oxidation starting with cinnamyl alcohol (Figure 2b). This observation suggests that Pt catalysed oxidation of the aldehyde controls final acid production from the alcohol. However, when cascade oxidation is attempted from cinnamyl alcohol over Pt, much of the reactively-formed aldehyde is hydrogenated to 3-phenylpropionaldehyde due to surface hydrogen released in the first oxidative dehydrogenation step and the high activity of platinum for $\mathrm{C}=\mathrm{C}$ hydrogenation ${ }^{41-43}$, and subsequently oxidised to 3-phenylpropanoic acid (Figure S10a). Previous studies have identified surface $\mathrm{PdO}$ and $\mathrm{PtO}_{2}$ as the active species responsible for the selective oxidation of cinnamyl alcohol to cinnamaldehyde. ${ }^{16-17,44-45}$ High selectivity of the monometallic Pd catalyst to cinnamaldehyde (Figure 3a) therefore implies surface $\mathrm{PdO}$ is present even at long residence times (high conversion). In contrast, selectivity to reactively-formed cinnamaldehyde initially decreases with residence time (alcohol conversion) for the monometallic Pt and dual/mixed beds. This reflects an increased probability of cinnamaldehyde oxidation to cinnamic acid (apparent from the coincident rise in cinnamic acid seen in Figure 2b) at longer residence times. However, for $\tau>15$ min, cinnamaldehyde selectivity increases over the monometallic Pt bed, suggesting that the second step of the cascade is now disfavoured. One explanation for this reversal is that long residence times promote (partial) in-situ reduction of surface $\mathrm{PtO}_{2}$, and hence loss of the requisite active site for oxygen insertion by a Mars-van Krevelen mechanism. XPS analysis of catalysts from the flow reactor confirmed the monometallic Pd catalyst was more resistant to surface oxide reduction than its Pt counterpart (Figure S16) in accordance with their standard reduction potentials ( 0.95 vs. $1.00 \mathrm{eV}$ respectively) ${ }^{46} \mathrm{In}$-situ reduction of surface $\mathrm{PtO}_{2}$ 
is an expected consequence of high cinnamyl alcohol conversion, and hence surface hydrogen concentrations, which also drive significant 3-phenylpropanoic acid formation (Figure S10a). A recent study of cinnamaldehyde selective oxidation over $\mathrm{Pt} / \mathrm{SiO}_{2}$ demonstrated that reaction temperatures $>90{ }^{\circ} \mathrm{C}$ increase $\mathrm{PtO}_{2}$ reduction and concomitant decarbonylation and $\mathrm{C}=\mathrm{C} / \mathrm{C}=\mathrm{O}$ hydrogenation in competition with production of the desired cinnamic acid. ${ }^{24}$

\section{Cinnamyl alcohol $\rightarrow$ Cinnamaldehyde}

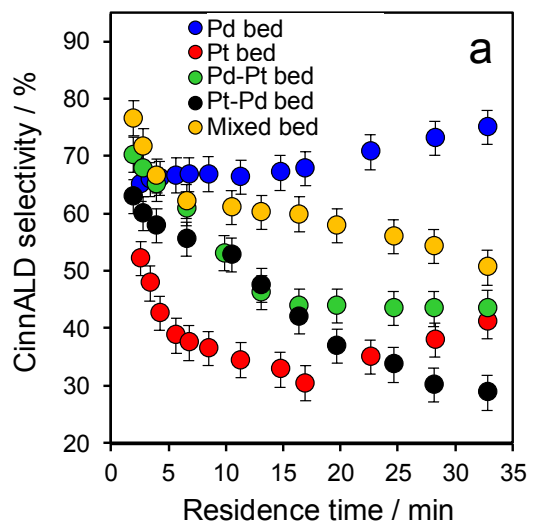

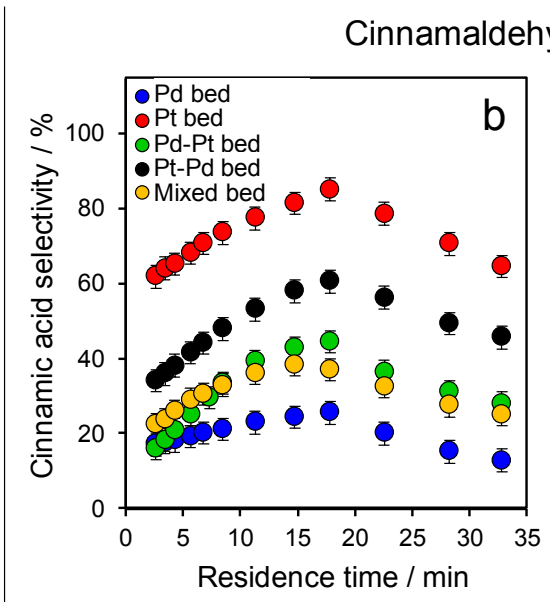

Figure 3. The influence of residence time on (a) cinnamaldehyde selectivity from cinnamyl alcohol selective oxidation in flow, and (b-c) cinnamic acid and styrene selectivity from cinnamaldehyde selective oxidation in flow over mono- and twocomponent catalyst beds. Reaction conditions: $50 \mathrm{mg}$ of each catalyst component, $90{ }^{\circ} \mathrm{C}, 5$ bar $\mathrm{O}_{2}, 168 \mathrm{mM}$ cinnamyl alcohol or cinnamaldehyde in toluene, liquid flow rates 0.1 to $2.5 \mathrm{~cm}^{3} \cdot \mathrm{min}^{-1}, 7 \mathrm{~h}$ on-stream.

We can now rationalise the performance of monometallic beds, mixed and sequential dual beds as follows. Palladium alone is active and selective for cinnamyl alcohol oxidation to cinnamaldehyde but cannot perform the second step of the cascade oxidation to produce cinnamic acid. Platinum alone exhibits modest activity for cinnamyl alcohol selective oxidation to cinnamaldehyde, but high activity for oxidation of the latter to cinnamic acid. Hence neither metal alone can catalyse both steps of the cascade with high activity and selectivity. Kinetic modelling of the dual bed configurations was performed using our previously proposed mechanism ${ }^{16}$ tested against batch reaction data. Good agreement was observed between experimental results (Figure S13) and our simulated data (Figure S18), providing quantitative validation for the mechanism. Corresponding initial rate constants derived from this batch data (Tables S3-4) and simulated CinnOH conversion and product yields confirm that placing a Pd catalyst upstream of a Pt catalyst enables high concentrations of cinnamaldehyde formed in the first bed to transfer downstream to the second bed wherein they are efficiently oxidised to cinnamic acid (Table 1 and Figure S19). The predicted total $\mathrm{CinnOH}$ yield for the Pd-Pt sequential dual bed of $14.2 \%$ is almost identical to the measured yield of $15 \%$ (Figure 2c). Modelling also confirms that the reverse bed sequence yields a mix of acid and aldehyde from an upstream Pt 
catalyst, with a significant proportion of this reactively-formed aldehyde undergoing subsequent decarbonylation to styrene over a downstream Pd catalyst, as seen in Figure 3c (and any unreacted cinnamyl alcohol exiting the first bed only able to form additional aldehyde, not acid, over the second). A physical mixture of the two catalysts, which offers no control over the sequence in which either alcohol or reactively-formed aldehyde encounter each metal, is predicted to offer an overall cinnamic acid yield intermediate between that of two monometallic beds due to modest aldehyde formation (predominantly from alcohol oxidation over palladium, as seen experimentally in Figure 3a) and modest acid production (predominantly from aldehyde oxidation over platinum, seen in Figure 3b). Additional simulations using the validated kinetic model demonstrate that cinnamic acid production is a strong function of Pd:Pt molar ratio for a fixed total catalyst mass in the Pd-Pt sequential dual bed configuration, with the maximum yield obtained for a $\mathrm{Pd}: \mathrm{Pt}=1: 3$ (Figure S20).

Table 1. Simulated cascade aerobic oxidation of cinnamyl alcohol from different bimetallic reactor configurations.

\begin{tabular}{|c|c|c|c|c|c|c|}
\hline \multirow{3}{*}{ Reactor configuration ${ }^{\mathrm{a}}$} & \multicolumn{3}{|l|}{1 st reactor bed } & \multicolumn{3}{|l|}{2 nd reactor bed } \\
\hline & \multirow[t]{2}{*}{$\begin{array}{l}\text { CinnOH conversion } \\
/ \%\end{array}$} & \multicolumn{2}{|c|}{$\begin{array}{l}\text { Product yield } \\
/ \%\end{array}$} & \multirow[t]{2}{*}{$\begin{array}{l}\text { CinnOH conversion } \\
/ \%\end{array}$} & \multicolumn{2}{|c|}{$\begin{array}{l}\text { Total product yield } \\
/ \%\end{array}$} \\
\hline & & CinnALD & CinnAcid & & CinnALD & CinnAcid \\
\hline Pd-Pt dual bed & 42.45 & 37.04 & 0.01 & 0.22 & 19.81 & 14.22 \\
\hline Pt-Pd dual bed & 30.29 & 19.91 & 0.80 & 4.53 & 17.68 & 0.85 \\
\hline PdPt single bed & 41.80 & 26.80 & 2.39 & & & \\
\hline
\end{tabular}

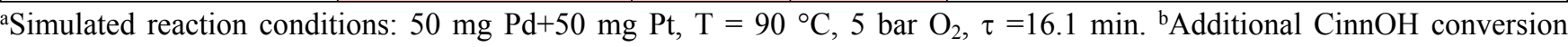
occurring within the second bed.

A key finding from our Pt-Pd sequential dual bed study is the significant benefit to be accrued by partitioning each step of the reaction. As previously highlighted, the staged addition of Pd followed ( $5 \mathrm{~h}$ later) by Pt catalysts in batch was superior to a physical mixture of both introduced at the start of reaction (Figure 1a). Reactively-formed cinnamaldehyde accumulated during the first $5 \mathrm{~h}$ reaction over the Pd catalyst underwent subsequent oxidation to cinnamic acid upon addition of the Pt catalyst (Figure 1a and Figure S21); staggering the addition sequence increased the cinnamic acid yield to $17 \%$ (versus $3 \%$ when both catalysts were pre-mixed at the beginning of the reaction). This confirms that decoupling the two reaction steps 
(alcohol $\rightarrow$ aldehyde and aldehyde $\rightarrow$ acid) either spatially in a dual bed flow reactor, or temporally in a batch reactor, can promote catalytic cascades.

\section{CONCLUSIONS}

Cascade (aerobic) selective oxidation of an alcohol to carboxylic acid through close-coupling of dual heterogeneous catalyst beds is demonstrated. Judicious arrangement of separate Pd/SBA-15 and Pt/SBA-15 reactor beds delivers a stable $84 \%$ yield of cinnamic acid from cinnamyl alcohol under reagent/base-free mild conditions for $>14,000$ turnovers, despite both catalysts being individually inactive for this reaction, with negligible deactivation for $>5 \mathrm{~h}$ on-stream. This represents a 20 -fold yield enhancement compared to that obtained by a physical mixture of the two catalysts in a batch reactor, which also results in their rapid deactivation. Although we have exploited contiguous reactor beds in this work, since previous batch ${ }^{24,27}$ and the present flow studies show minimal esterification of allylic alcohols by unsaturated acid oxidation products, it should be possible to operate with the beds separated in a close-coupled manner (e.g. located within different heating zones) to enable finer process control. Kinetic modelling verifies that cinnamic acid productivity is quantitatively predicted by the performance of each catalyst in isolation for each step of the cascade; this is a key finding, since the individual performances of our Pd/SBA-15 and Pt/SBA-15 catalysts for the oxidation of diverse allylic alcohols ${ }^{17}$ and aldehydes ${ }^{24}$ respectively are already known, and hence the cascade synthesis of diverse unsaturated carboxylic acids from their corresponding unsaturated alcohols should be readily achievable. Our approach obviates the need to design/fabricate new multifunctional catalysts, by opening a pathway to construct modular catalytic cascades from the existing literature. Future efforts will address the staged introduction of reactants, independent temperature control of each catalyst bed, and extending the length of multi-step cascades.

\section{METHODS}

\section{Support synthesis}

SBA-15 was synthesised according to literature methods. ${ }^{47} 10 \mathrm{~g}$ Pluronic P123 was dissolved in $75.5 \mathrm{~cm}^{3}$ water and $291.5 \mathrm{~cm}^{3}$ of $2 \mathrm{M}$ hydrochloric acid under stirring at $35^{\circ} \mathrm{C}$. Tetraethylorthosilicate $\left(15.5 \mathrm{~cm}^{3}\right)$ was subsequently added and left stirring for $20 \mathrm{~h}$. The resulting gel was aged for $24 \mathrm{~h}$ at $80^{\circ} \mathrm{C}$ without agitation. The solid was filtered, washed with $1000 \mathrm{~cm}^{3}$ water, and dried at room temperature before calcination at $500{ }^{\circ} \mathrm{C}$ for $6 \mathrm{~h}$ in air $\left(\operatorname{ramp} 1{ }^{\circ} \mathrm{C} \cdot \mathrm{min}^{-1}\right)$. The resulting silica exhibited the expected hexagonal close-packed $(p 6 \mathrm{~mm})$ arrangements of uniform $(\sim 5 \mathrm{~nm})$ mesopores.

\section{Catalyst synthesis}


$2 \mathrm{~g}$ batches of mesoporous SBA-15 were wetted with either aqueous ammonium tetrachloroplatinate (II) solution or aqueous tetraamine palladium(II) nitrate solution $\left(16 \mathrm{~cm}^{3}\right.$ with the precursor concentrations adjusted to achieve a nominal $1.0 \mathrm{wt} \% \mathrm{Pt}$ or $0.5 \mathrm{wt} \%$ Pd loading). The resulting slurries were stirred for $18 \mathrm{~h}$ at room temperature before heating to $50{ }^{\circ} \mathrm{C}$. Agitation was ceased after $5 \mathrm{~h}$, and the solids dried at $50{ }^{\circ} \mathrm{C}$ for $24 \mathrm{~h}$. The resulting powders were calcined at $500{ }^{\circ} \mathrm{C}$ for $4 \mathrm{~h}$ in air (ramp 10 $\left.{ }^{\circ} \mathrm{C} \cdot \mathrm{min}^{-1}\right)$ prior to reduction at $400{ }^{\circ} \mathrm{C}$ for $2 \mathrm{~h}\left(\operatorname{ramp~} 10{ }^{\circ} \mathrm{C} \cdot \mathrm{min}^{-1}\right)$ under $10 \mathrm{~cm}^{3} \cdot \mathrm{min}^{-1}$ flowing hydrogen.

\section{Catalyst characterisation}

Nitrogen porosimetry was undertaken on a Quantachrome Nova 2000e porosimeter, and analysis performed using NovaWin software version 11 . Samples were degassed at $120^{\circ} \mathrm{C}$ for $2 \mathrm{~h}$ prior to analysis by $\mathrm{N}_{2}$ physisorption. Adsorption-desorption isotherms were recorded for both parent and metal-impregnated silicas. BET surface areas were calculated over the relative pressure range 0.01-0.2. Wide angle XRD patterns were recorded on a Bruker D8 Advance diffractometer with $\mathrm{Cu} \mathrm{K}_{\alpha}(1.54$ $\AA ̊$ ) source, calibrated against a Si standard, between $2 \theta=20-90^{\circ}$ with a step size of $0.02^{\circ}$. Low angle X-ray patterns were recorded for $2 \theta=0.3-8^{\circ}$ with a step size of $0.02^{\circ}$. The Scherrer equation was used to calculate volume-averaged $\mathrm{Pd}$ and $\mathrm{Pt}$ particle sizes from line broadening. XPS was performed on a Kratos Axis HSi X-ray photoelectron spectrometer fitted with a charge neutraliser and magnetic focusing lens employing $\mathrm{Al} \mathrm{K}_{\alpha}$ monochromated radiation $(1486.7 \mathrm{eV})$. Spectral fitting was performed using CasaXPS version 2.3.14, with binding energies corrected to the C 1s peak at 284.6 eV. Pt 4f and Pd 3d XP spectra were fitted using asymmetric Doniach Sunjic lineshapes. Pd and Pt dispersions were determined by CO chemisorption on a Quantachrome ChemBET3000 system. Catalysts were outgassed at $150{ }^{\circ} \mathrm{C}$ under $20 \mathrm{~cm}^{3} \cdot \mathrm{min}^{-1}$ flowing He for $1 \mathrm{~h}$, prior to $150{ }^{\circ} \mathrm{C}$ reduction under $10 \mathrm{~cm}^{3} \cdot \mathrm{min}^{-1}$ flowing hydrogen for $1 \mathrm{~h}$ before room temperature analysis. A CO:metal surface $_{\text {. }}$ stoichiometry of 0.5 and 0.68 was assumed for $\mathrm{Pd}$ and Pt respectively. Note that this reduction protocol is milder than that employed during impregnation and does not induce additional particle sintering. Metal loadings were determined using inductively coupled plasma optical emission spectroscopy (ICP-AES); on an iCAP 700 ICP-AES spectrometer. Samples were dissolved via microwave assisted digestion prior to analysis; $20 \mathrm{mg}$ powder sample was placed into the stirrer microwave cell, along with $100 \mathrm{mg}$ ammonium fluoride and $5 \mathrm{~cm}^{3}$ nitric acid (70\%) and $1 \mathrm{~cm}^{3} \mathrm{HCl}(37 \%)$. Following microwave irradiation $\left(190{ }^{\circ} \mathrm{C}, 20 \mathrm{~min}, 300 \mathrm{~W}\right)$ in-situ generated $\mathrm{HF}$ was neutralised with $1 \mathrm{~cm}^{3}$ boric acid solution (4\%). The spectrometer response was calibrated through sequential analysis of a series of elemental standards (1000 ppm AAS standards purchased for Sigma Aldrich and Fisher Scientific), and samples diluted 10-fold in deionised water prior to analysis. $\mathrm{R}^{2}$ values from calibration were above 0.997 in all cases. Negligible metal leaching was observed in flow or batch for any configuration or residence time (Table S2). 


\section{Flow selective oxidation}

Continuous flow catalyst testing was conducted using a commercial Uniqsis FlowSyn reactor, comprising a gas-liquid addition module (GAM II) and packed bed microreactor with downstream backflow pressure regulator. Oxygen (5 bar) was delivered via an in-line Brooks mass flow controller and back pressure regulator, while an integral HPLC pump delivered a $168 \mathrm{mM}$ cinnamyl alcohol or cinnamaldehyde (in toluene) liquid stream at flow rates between $0.1 \mathrm{~cm}^{3} \cdot \mathrm{min}^{-1}$ to $2.5 \mathrm{~cm}^{3} . \mathrm{min}^{-1}$. Liquid and gas feeds were pre-mixed before introduction to the microreactor packed bed via the GAM II module which features a preheated semi-permeable polymer coil and reactor mandrel to ensure efficient gas-liquid pre-mixing and pre-heating to $90{ }^{\circ} \mathrm{C}$ prior to contact with the catalyst. Catalysts were diluted with quartz beads (Sigma Aldrich, mesh size $=325$ ) to minimise back pressure, and packed within a $10 \mathrm{~mm}$ i.d. x $100 \mathrm{~mm}$ OMNIFIT ${ }^{\circledR}$ glass column to give a total bed volume of $3.4 \mathrm{~cm}^{3}(\mathrm{common}$ for all catalyst beds), held in place between quartz wool plugs at either end of the column; catalyst particles were crushed and sieved to the same size fraction (325 mesh) as the quartz pellets. The total catalyst mass is detailed in figures. The reactor was oriented vertically and the oxygen-saturated liquid stream fed in an up-flow direction to minimise settling and maximise permeation of the reaction mixture through the catalyst bed. Neither fluidisation nor compaction of the catalyst bed was observed under any conditions. The exit stream passed through a needle valve and backflow regulator, with excess gas vented prior to off-line liquid analysis using a Varian $3800 \mathrm{GC}$ with 8400 autosampler fitted with a (30 m x $0.25 \mathrm{~mm} \times 0.25 \mu \mathrm{m}) \mathrm{VF}$ $5 \mathrm{~ms}$ factor four column. The residence time distribution $F(t)$ was determined from:

$F(t)=\left\{\left([\text { Substrate }]_{\mathrm{t}}+[\text { Products }]_{\mathrm{t}}\right) /[\text { Substrate }]_{\text {inlet }}\right\} / \tau$

Conversion in flow was calculated from Equation 2, where $\mathrm{m}_{\text {outlet }}$ is the molar flow rate of substrate exiting the reactor and $\mathrm{m}_{\text {inlet }}$ is molar flow rate of substrate input to the reactor. Selectivity was calculated from Equation 3 based on the five liquid phase products observed, where $\mathrm{m}_{x=i}$ is the mmol of product $i$ exiting the reactor per unit time, and $\Sigma \mathrm{m}_{x}$ denotes the total mmol of products exiting the reactor per unit time:

$\%$ Conversion $=\left\{\left(\mathrm{m}_{\text {inlet }}-\mathrm{m}_{\text {outlet }}\right) /\left(\mathrm{m}_{\text {inlet }}\right)\right\} \times 100$

$\%$ Selectivity $=\left\{\left(\mathrm{n}_{x=i}\right) /\left(\Sigma \mathrm{n}_{x}\right)\right\} \times 100$

where $i=$ cinnamic acid, 3-phenylpropan-1-ol, 3-phenylpropanoic acid, styrene, cinnamyl esters and cinnamaldehyde. For batch, conversion and selectivity were derived from the absolute molar concentration of reactant at a given time relative to the 
initial concentration, and ratio of the molar concentration of any individual product to the total product concentration at a given time, respectively. Yield (molar productivity relative to reactant input) and Turnover Frequency (TOF) are defined in Equations 4 and 5 below:

$\%$ Yield $=\{\%$ Conversion $\mathrm{x} \%$ Selectivity $\} / 100$

$\mathrm{TOF}=\mathrm{mmol}_{\text {Substrate converted }} \cdot \mathrm{h}^{-1} / \mathrm{mmol}_{\text {Surface } \mathrm{Mx}+}$

where $\mathrm{mmol}_{\text {Surface } \mathrm{Mx}+}$ was determined from CO chemisorption and ICP-AES (to derive the total number of surface metal atoms) and XPS (to derive the fraction of these surface atoms present as an oxide in the as-prepared catalysts).

\section{Batch selective oxidation}

Catalyst testing was performed using a Parr $5513100 \mathrm{~cm}^{3}$ stainless steel stirred batch autoclave at 5 bar $\mathrm{O}_{2}$ pressure on a 50 $\mathrm{cm}^{3}$ scale at $90^{\circ} \mathrm{C} .200 \mathrm{mg}$ of monometallic (Pd or Pt) catalyst or a $100 \mathrm{mg}$ each physical mixture (Pd+Pt) of catalysts (common total metal content) were added to a reaction mixture containing $16.8 \mathrm{mmol}$ cinnamyl alcohol or cinnamaldehyde substrate, $0.1 \mathrm{~cm}^{3}$ mesitylene internal standard and $50 \mathrm{~cm}^{3}$ toluene solvent under $1000 \mathrm{rpm}$ stirring. Reactions were sampled periodically via a dip-tube and analysed by off-line using a Varian 3800GC with 8400 autosampler fitted with a (30 m x $0.25 \mathrm{~mm} \times 0.25$ $\mu \mathrm{m})$ VF-5ms Factor Four column.

\section{Kinetic modelling}

A mechanism including a set of surface reactions was developed as shown in Table $\mathbf{S} \mathbf{4}$ based on the mechanism proposed by Durndell et al. ${ }^{16}$ Rate expressions were generated and rate coefficients optimised using an unconstrained nonlinear optimization function, fminsearch, built in MatLab R2018b by minimising an objective function of the residual sum of squares (RSS):

$R S S=\sum_{i} \sum_{t}\left(C_{i, t, s i m}-C_{i, t, e x p}\right)^{2}$

where $C_{i, t, s i m}$ and $C_{i, t, e x p}$ are the simulated and experimental concentrations in mole $/ \mathrm{m}^{3}$ of component $i$ at time $t$ in seconds, respectively. The mechanism was validated by modelling the experimental results catalysed by $100 \mathrm{mg}$ and $200 \mathrm{mg}$ catalysts of Pd, Pt, and the physical mixture of both Pd and Pt in batch reactors. Kinetic modelling of experiments in flow reactors with single-bed configurations was performed using the validated mechanism and optimised rate coefficients in batch reactors as 
initiates, and kinetic modelling with dual bed configurations was then performed using the optimised rate coefficients obtained from the single-bed flow reactors.

\section{ASSOCIATED CONTENT}

Supporting Information. Catalyst characterisation, batch and continuous flow reaction profiles, kinetic models and rate constants. This material is available free of charge via the Internet at http://pubs.acs.org.

\section{AUTHOR INFORMATION}

Corresponding Author

*adam.lee2@rmit.edu.au

ORCID

Adam Lee: 0000-0002-2153-1391

Karen Wilson: 0000-0003-4873-708X

\section{ACKNOWLEDGMENTS}

This work was supported by the Engineering and Physical Sciences Research Council under award EP/K014749/1.

\section{REFERENCES}

1. Climent, M. J.; Corma, A.; Iborra, S., Conversion of biomass platform molecules into fuel additives and liquid hydrocarbon fuels. Green Chem. 2014, 16 (2), 516-547.

2. Jerome, F.; Barrault, J., Renewable carbon and eco-efficient processes. Green Chem. 2013, 15 (11), 3014-3014.

3. Anastas, P.; Eghbali, N., Green Chemistry: Principles and Practice. Chem. Soc. Rev. 2010, 39 (1), 301-312.

4. Nicolaou, K.; Edmonds, D. J.; Bulger, P. G., Cascade reactions in total synthesis. Angew. Chem. Int.-Ed. 2006, 45 (43), 7134-7186.

5. Morgan, P. J.; Lorenzini, F.; Marr, A. C., Conversion of Biomass Using Simultaneous Chemo- and Bio-catalysis. In Production of Biofuels and Chemicals with Bifunctional Catalysts, Fang, Z.; Smith Jr, R. L.; Li, H., Eds. Springer Singapore: Singapore, 2017; pp 347-378.

6. Lamberth, C., Bioactive carboxylic compound classes: pharmaceuticals and agrochemicals. John Wiley \& Sons: 2016.

7. Chen, G.-J.; Li, X.-B.; Zhao, C.-C.; Ma, H.-C.; Kan, J.-L.; Xin, Y.-B.; Chen, C.-X.; Dong, Y.-B., Ru Nanoparticles-Loaded Covalent Organic Framework for Solvent-Free One-Pot Tandem Reactions in Air. Inorg. Chem. 2018, 57 (5), 2678-2685.

8. Lu, L.-Q.; Chen, J.-R.; Xiao, W.-J., Development of Cascade Reactions for the Concise Construction of Diverse Heterocyclic Architectures. Acc. Chem. Res. 2012, 45 (8), 1278-1293.

9. Zhao, M.; Deng, K.; He, L.; Liu, Y.; Li, G.; Zhao, H.; Tang, Z., Core-Shell Palladium Nanoparticle@Metal-Organic Frameworks as Multifunctional Catalysts for Cascade Reactions. J. Am. Chem. Soc. 2014, 136 (5), 1738-1741.

10. Hoskins, J. A., The occurrence, metabolism and toxicity of cinnamic acid and related compounds. J. Appl. Toxicol. 1984, $4(6), 283-292$. 
11. Yamada, S.; Nabe, K.; Izuo, N.; Nakamichi, K.; Chibata, I., Production of 1-Phenylalanine from trans-Cinnamic Acid with Rhodotorula glutinis Containing l-Phenylalanine Ammonia-Lyase Activity. Appl. Environ. Microbiol. 1981, 42 (5), $773-778$. 12. Yang, Y.-H.; Raku, T.; Song, E.; Park, S.-H.; Yoo, D.; Park, H.-Y.; Kim, B.-G.; Kim, H.-J.; Lee, S.-H.; Kim, H.-S.; Tokiwa, Y., Lipase catalyzed reaction of L-ascorbic acid with cinnamic acid esters and substituted cinnamic acids. Biotechnol. Bioprocess Eng. 2012, 17 (1), 50-54.

13. Karimi, B.; Khorasani, M.; Vali, H.; Vargas, C.; Luque, R., Palladium nanoparticles supported in the nanospaces of imidazolium-based bifunctional PMOs: The role of plugs in selectivity changeover in aerobic oxidation of alcohols. ACS Catal. 2015, 5 (7), 4189-4200.

14. Gemoets, H. P.; Su, Y.; Shang, M.; Hessel, V.; Luque, R.; Noel, T., Liquid phase oxidation chemistry in continuous-flow microreactors. Chem. Soc. Rev. 2016, 45 (1), 83-117.

15. Parmeggiani, C.; Matassini, C.; Cardona, F., A step forward towards sustainable aerobic alcohol oxidation: new and revised catalysts based on transition metals on solid supports. Green Chem. 2017, 19 (9), 2030-2050.

16. Durndell, L. J.; Parlett, C. M. A.; Hondow, N. S.; Wilson, K.; Lee, A. F., Tunable Pt nanocatalysts for the aerobic selox of cinnamyl alcohol. Nanoscale 2013, 5 (12), 5412-5419.

17. Parlett, C. M. A.; Bruce, D. W.; Hondow, N. S.; Lee, A. F.; Wilson, K., Support-Enhanced Selective Aerobic Alcohol Oxidation over Pd/Mesoporous Silicas. ACS Catal. 2011, 1 (6), 636-640.

18. Besson, M.; Gallezot, P., Selective oxidation of alcohols and aldehydes on metal catalysts. Catal. Today 2000, 57 (1), $127-$ 141.

19. Muzart, J., Palladium-catalysed oxidation of primary and secondary alcohols. Tetrahedron 2003, 59 (31), 5789-5816.

20. Anderson, R.; Griffin, K.; Johnston, P.; Alsters, P. L., Selective oxidation of alcohols to carbonyl compounds and carboxylic acids with platinum group metal catalysts. Adv. Synth. Catal. 2003, 345 (4), 517-523.

21. Powell, A. B.; Stahl, S. S., Aerobic Oxidation of Diverse Primary Alcohols to Methyl Esters with a Readily Accessible Heterogeneous Pd/Bi/Te Catalyst. Org. Lett. 2013, 15 (19), 5072-5075.

22. Mannel, D. S.; Ahmed, M. S.; Root, T. W.; Stahl, S. S., Discovery of Multicomponent Heterogeneous Catalysts via Admixture Screening: PdBiTe Catalysts for Aerobic Oxidative Esterification of Primary Alcohols. J. Am. Chem. Soc. 2017, 139 (4), 1690-1698.

23. Mannel, D. S.; King, J.; Preger, Y.; Ahmed, M. S.; Root, T. W.; Stahl, S. S., Mechanistic Insights into Aerobic Oxidative Methyl Esterification of Primary Alcohols with Heterogeneous PdBiTe Catalysts. ACS Catal. 2018, 8 (2), 1038-1047.

24. Durndell, L. J.; Cucuzzella, C.; Parlett, C. M. A.; Isaacs, M. A.; Wilson, K.; Lee, A. F., Platinum catalysed aerobic selective oxidation of cinnamaldehyde to cinnamic acid. Catal. Today 2018.

25. Davis, S. E.; Zope, B. N.; Davis, R. J., On the mechanism of selective oxidation of 5-hydroxymethylfurfural to 2, 5furandicarboxylic acid over supported $\mathrm{Pt}$ and Au catalysts. Green Chem. 2012, 14 (1), 143-147.

26. Grunwaldt, J.-D.; Keresszegi, C.; Mallat, T.; Baiker, A., In situ EXAFS study of Pd/Al2O3 during aerobic oxidation of cinnamyl alcohol in an organic solvent. J. Catal. 2003, 213 (2), 291-295.

27. Parlett, C. M.; Isaacs, M. A.; Beaumont, S. K.; Bingham, L. M.; Hondow, N. S.; Wilson, K.; Lee, A. F., Spatially orthogonal chemical functionalization of a hierarchical pore network for catalytic cascade reactions. Nat. Mater. 2016, 15 (2), 178.

28. Ye, X.; Johnson, M. D.; Diao, T.; Yates, M. H.; Stahl, S. S., Development of safe and scalable continuous-flow methods for palladium-catalyzed aerobic oxidation reactions. Green Chem. 2010, 12 (7), 1180-1186.

29. Brzozowski, M.; O’Brien, M.; Ley, S. V.; Polyzos, A., Flow Chemistry: Intelligent processing of gas-liquid transformations using a tube-in-tube reactor. Acc. Chem. Res. 2015, 48 (2), 349-362.

30. Plutschack, M. B.; Pieber, B. u.; Gilmore, K.; Seeberger, P. H., The Hitchhiker's Guide to Flow Chemistryll. Chem. Rev. 2017, 117 (18), 11796-11893.

31. Vanoye, L.; Aloui, A.; Pablos, M.; Philippe, R.; Percheron, A.; Favre-Réguillon, A.; de Bellefon, C., A safe and efficient flow oxidation of aldehydes with O2. Org. Lett. 2013, 15 (23), 5978-5981.

32. Muzen, A.; Fraguío, M. S.; Cassanello, M. C.; Ayude, M. A.; Haure, P. M.; Martínez, O. M., Clean oxidation of alcohols in a trickle-bed reactor with liquid flow modulation. Ind. Eng. Chem. Res. 2005, 44 (14), 5275-5284.

33. Osterberg, P. M.; Niemeier, J. K.; Welch, C. J.; Hawkins, J. M.; Martinelli, J. R.; Johnson, T. E.; Root, T. W.; Stahl, S. S., Experimental limiting oxygen concentrations for nine organic solvents at temperatures and pressures relevant to aerobic oxidations in the pharmaceutical industry. Org. Process Res. Dev. 2014, 19 (11), 1537-1543.

34. Gavriilidis, A.; Constantinou, A.; Hellgardt, K.; Hii, K. K.; Hutchings, G. J.; Brett, G. L.; Kuhn, S.; Marsden, S. P., Aerobic oxidations in flow: opportunities for the fine chemicals and pharmaceuticals industries. React. Chem. Eng. 2016, 1 (6), 595612.

35. Pieber, B.; Kappe, C. O., Aerobic Oxidations in Continuous Flow. In Organometallic Flow Chemistry, Noël, T., Ed. Springer International Publishing: Cham, 2016; pp 97-136.

36. Sharma, Y.; Moolya, S.; Joshi, R.; Kulkarni, A., Continuous flow telescopic oxidation of alcohols via generation of chlorine and hypochlorite. React. Chem. Eng. 2017, 2 (3), 304-308.

37. de Jesús, J. C.; Zaera, F., Adsorption and thermal chemistry of acrolein and crotonaldehyde on Pt (111) surfaces. Surf. Sci. 1999, $430(1-3), 99-115$.

38. Ide, M. S.; Falcone, D. D.; Davis, R. J., On the deactivation of supported platinum catalysts for selective oxidation of alcohols. J. Catal. 2014, 311, 295-305. 
39. Keresszegi, C.; Mallat, T.; Grunwaldt, J.-D.; Baiker, A., A simple discrimination of the promoter effect in alcohol oxidation and dehydrogenation over platinum and palladium. J. Catal. 2004, 225 (1), 138-146.

40. Bowker, M.; Cookson, L.; Bhantoo, J.; Carley, A.; Hayden, E.; Gilbert, L.; Morgan, C.; Counsell, J.; Yaseneva, P., The decarbonylation of acetaldehyde on Pd crystals and on supported catalysts. Appl. Catal. A Gen. 2011, 391 (1), 394-399.

41. Handjani, S.; Marceau, E.; Blanchard, J.; Krafft, J.-M.; Che, M.; Mäki-Arvela, P.; Kumar, N.; Wärnå, J.; Murzin, D. Y., Influence of the support composition and acidity on the catalytic properties of mesoporous SBA-15, Al-SBA-15, and Al2O3supported Pt catalysts for cinnamaldehyde hydrogenation. J. Catal. 2011, 282 (1), 228-236.

42. Vergunst, T.; Kapteijn, F.; Moulijn, J., Kinetics of cinnamaldehyde hydrogenation-concentration dependent selectivity. Catal. Today 2001, 66 (2-4), 381-387.

43. Samant, P. V.; Pereira, M. F.; Figueiredo, J. L., Mesoporous carbon supported Pt and Pt-Sn catalysts for hydrogenation of cinnamaldehyde. Catal. Today 2005, 102, 183-188.

44. Lee, A. F.; Ellis, C. V.; Naughton, J. N.; Newton, M. A.; Parlett, C. M. A.; Wilson, K., Reaction-Driven Surface Restructuring and Selectivity Control in Allylic Alcohol Catalytic Aerobic Oxidation over Pd. J. Am. Chem. Soc. 2011, 133 (15), 5724-5727.

45. Lee, A. F.; Wilson, K., Structure-reactivity correlations in the selective aerobic oxidation of cinnamyl alcohol: in situ XAFS. Green Chem. 2004, 6 (1), 37-42.

46. Bard, A., Standard potentials in aqueous solution. Routledge: 2017.

47. Zhao, D.; Feng, J.; Huo, Q.; Melosh, N.; Fredrickson, G. H.; Chmelka, B. F.; Stucky, G. D., Triblock Copolymer Syntheses of Mesoporous Silica with Periodic 50 to 300 Angstrom Pores. Science 1998, 279 (5350), 548-552. 


\section{Table of contents entry}

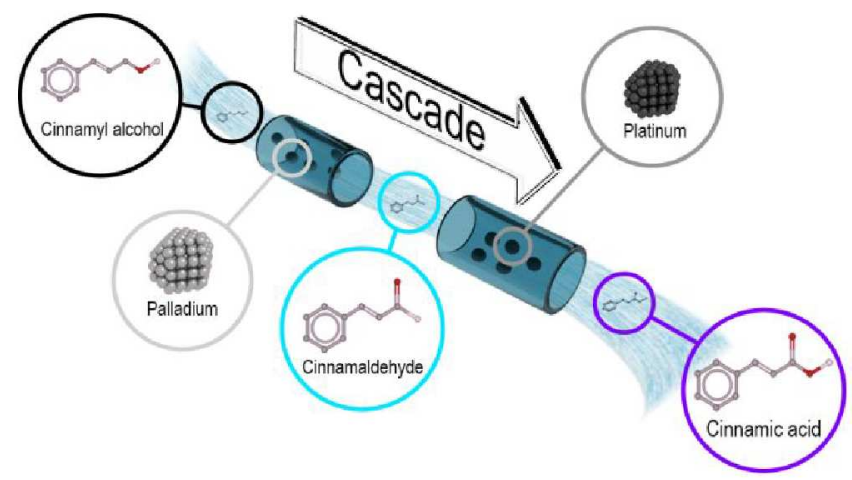

16

17

18

19

20

21

22

23

24

25

26

27

28

29

30

31

32

33

34

35

36

37

38

39

40

41

42

43

44

45

46

47

48

49

50

51

57

58

59 